\title{
Desempenho e avaliação econômica da terminação de tourinhos em confinamento alimentados com diferentes níveis de concentrado na dieta
}

\author{
Regis Luis Missio ${ }^{1}$, Ivan Luiz Brondani ${ }^{2}$, Leandro da Silva Freitas ${ }^{1}$, Rafael Henrique Sachet ${ }^{1}$, \\ José Henrique Souza da Silva ${ }^{2}$, João Restle ${ }^{3}$
}

1 Programa de Pós-Graduação em Zootecnia - UFSM

2 Departamento de Zootecnia - UFSM. Pesquisador CNPq.

${ }_{3}^{3}$ Pesquisador Visitante - UFG. Pesquisador CNPq.

\begin{abstract}
RESUMO - Este estudo foi conduzido para avaliar o desempenho animal e a viabilidade econômica da utilização de diferentes níveis de concentrado na dieta no confinamento de tourinhos para abate entre 14-16 meses de idade. Foram utilizados 16 bovinos não-castrados alimentados com 22, 40, 59 ou 79\% de concentrado na dieta, distribuídos em delineamento inteiramente ao acaso, com quatro repetições por tratamento. A idade e o peso médio inicial dos animais foram de 9,32 meses e $192 \mathrm{~kg}$, respectivamente. A idade de abate, o peso final, o consumo de fibra em detergente neutro, a conversão alimentar e a lucratividade mensal diminuíram com o aumento do nível de concentrado. O consumo de matéria seca em porcentagem do peso vivo e do tamanho metabólico apresentaram comportamento quadrático, aumentando até os níveis de 67 e $75 \%$ de concentrado na dieta, respectivamente. O consumo de energia digestível e o ganho de peso vivo médio diário apresentaram aumentos lineares com a elevação do nível de concentrado. O aumento do nível de concentrado da dieta de 22 para 79\% aumenta o desempenho animal, mas reduz a lucratividade da terminação de tourinhos dos 14 aos 16 meses de idade.
\end{abstract}

Palavras-chave: composição genética, consumo, custos, lucratividade, silagem de milho

\section{Performance and economic evaluation of young finished feedlot bulls fed different concentrate levels in the diet}

\begin{abstract}
This study was conducted to evaluate the performance and economic viability of young bulls slaughtered at 14-16 months old, fed on different concentrate levels in the diet. Sixteen young bulls were randomly distributed and fed with $22,40,59$ or $79 \%$ concentrate in the diet, resulting in four replications per treatment. The initial age and weight were 9.32 months and $192.44 \mathrm{~kg}$, respectively. Final age, final weight, neutral fiber detergent intake, feed conversion and monthly profit decreased with increasing concentrate levels. The dry matter intake as percentage of live weight and metabolic size showed quadratic variation, increasing to 67 and $75 \%$ concentrate in the diet, respectively. The digestible energy intake and average daily weight gain increased with increases in concentrate levels. The increase in the level of dietary concentrate from 22 to $79 \%$ increased the animal performance, but decreased the profitability of young finished feedlot bulls at 14-16 months old.
\end{abstract}

Key Words: corn silage, costs, genetic composition, intake, profitably

\section{Introdução}

O sistema tradicional de produção pecuária tem se mostrado economicamente pouco eficiente, obrigando os produtores à busca por alternativas que aumentem a lucratividade da propriedade. Nesse sentido, a redução da idade de abate para 14-16 meses pode proporcionar maior giro de capital investido, liberando áreas na propriedade de ciclo completo, aumentando o número de matrizes e resultando em maior produção de bezerros.
Na produção de animais superjovens, a preocupação é otimizar e viabilizar o desempenho (técnico e econômico) desses animais por meio do consumo de nutrientes, que pode ser manipulado pela relação volumoso:concentrado da dieta. Contudo, pesquisas com essa categoria animal, e mesmo aquelas com animais de outras categorias, com avaliação do desempenho e da economicidade de diferentes proporções de concentrado na dieta, são escassas, embora, para o produtor, o aspecto econômico seja o principal fator para determinação da quantidade de concentrado a ser utilizada. 
Outro agravante neste tipo de produção é que, após o planejamento e a implantação da intensificação, não é possível retornar ao sistema convencional sem perdas financeiras. Com isso, o surgimento de imprevistos de ordem econômica, climática, sanitária ou quaisquer outros que interfiram no desempenho animal programado nos períodos de cria e recria, acarreta baixos pesos vivos ao início do confinamento, o que pode aumentar o período de alimentação e onerar o investimento.

Este estudo foi realizado com o objetivo de determinar a relação volumoso:concentrado da dieta à base de silagem de milho que proporciona o melhor desempenho animal e lucratividade na terminação de bovinos não-castrados, confinados com peso vivo inicial médio de $192 \mathrm{~kg}$.

\section{Material e Métodos}

O trabalho foi realizado no período de 30/7/2005 a 13/3/2006, no Laboratório de Bovinocultura de Corte do Departamento de Zootecnia da Universidade Federal de Santa Maria, localizado na latitude de $29^{\circ} 43^{\prime}$ 'Sul e longitude $53^{\circ} 42^{\prime}$ Oeste, na Depressão Central do Rio Grande do Sul.

Foram utilizados 16 bovinos não-castrados contemporâneos, desmamados precocemente, mestiços CharolêsNelore, com aproximadamente 9,32 meses de idade e $192,44 \mathrm{~kg}$ de peso vivo inicial. Os animais foram confinados individualmente em baias cobertas de $12 \mathrm{~m}^{2}$, pavimentadas com concreto e providas de comedouros individualizados e bebedouros regulados com torneira-boia, e mantidos com dietas com 22, 40, 59 ou $79 \%$ de concentrado e silagem de milho como volumoso (híbrido BRS - 3150, cortado a $20 \mathrm{~cm}$ do solo, com $23 \%$ de grãos na MS ensilada).

Antecedendo o período experimental, os animais foram adaptados por 24 dias às instalações e dietas experimentais e, durante o período experimental (199 dias), foram alimentados à vontade, duas vezes ao dia (às 8 e às $17 \mathrm{~h}$ ). O volumoso foi distribuído no comedouro e sobre o mesmo foi colocado o concentrado, realizando a mistura em seguida. A dieta foi calculada para ser isoproteica, com $12 \%$ de proteína bruta (PB), para consumo de $3 \mathrm{~kg}$ de $\mathrm{MS} / 100 \mathrm{~kg}$ de PV. O concentrado foi constituído de grão de milho moído, farelo de soja, farelo de trigo, sal, calcário calcítico, ureia, monensina sódica e sulfato de amônio (Tabela 1). O consumo foi registrado diariamente por meio da pesagem dos alimentos e das sobras, mantendo-se oferta em $10 \%$ acima do consumo voluntário.

Os animais foram pesados individualmente, no início e ao final do período experimental (28 dias), após jejum de sólidos e líquidos de 14 horas. À medida que os animais
Tabela 1 - Composição das rações e custos dos ingredientes

\begin{tabular}{|c|c|c|c|c|c|}
\hline \multirow[t]{2}{*}{ Teor } & \multicolumn{4}{|c|}{ Nível de concentrado } & \multirow[t]{2}{*}{$\mathrm{R} \$ / \mathrm{t} M S$} \\
\hline & 22 & 40 & 59 & 79 & \\
\hline Silagem milho, \% & 78,00 & 60,00 & 41,00 & 21,00 & 70,00 \\
\hline Milho grãos, \% & 5,91 & 9,43 & 29,32 & 49,15 & 500,00 \\
\hline Farelo soja, \% & 3,53 & 4,11 & 2,58 & 0,32 & 600,00 \\
\hline Farelo trigo, \% & 10,75 & 24,27 & 24,79 & 26,97 & 270,00 \\
\hline Calcário calcítico, \% & 0,92 & 1,46 & 1,63 & 1,92 & 130,00 \\
\hline $\mathrm{NaCl}, \%$ & 0,33 & 0,32 & 0,32 & 0,32 & 280,00 \\
\hline Uréia, \% & 0,51 & 0,37 & 0,32 & 0,27 & 950,00 \\
\hline Monensina sódica, \% & 0,02 & 0,02 & 0,02 & 0,032 & $2.500,00$ \\
\hline Sulfato de amônio, \% & 0,03 & 0,02 & 0,02 & 0,02 & 250,00 \\
\hline \multicolumn{6}{|l|}{ Composição nutricional } \\
\hline Matéria seca, \% & 39,47 & 50,06 & 61,00 & 71,73 & - \\
\hline Matéria mineral, \% & 6,24 & 5,93 & 5,72 & 5,46 & - \\
\hline Proteína bruta, \% & 11,20 & 12,50 & 12,10 & 11,80 & - \\
\hline $\begin{array}{l}\text { Nutrientes digestíveis } \\
\text { totais, \%* }\end{array}$ & 65,30 & 66,70 & 70,60 & 74,20 & - \\
\hline $\begin{array}{l}\text { Energia digestível } \\
\mathrm{Mcal} / \mathrm{kg}^{* *}\end{array}$ & 2,87 & 2,94 & 3,11 & 3,27 & - \\
\hline $\begin{array}{l}\text { Fibra em detergente } \\
\text { neutro, } \%\end{array}$ & 48,00 & 43,80 & 38,10 & 28,70 & - \\
\hline $\begin{array}{l}\text { Fibra em detergente } \\
\text { ácido, \% }\end{array}$ & 22,60 & 19,40 & 13,10 & 6,90 & - \\
\hline NIDN, \% & 0,23 & 0,24 & 0,24 & 0,24 & - \\
\hline NIDA, \% & 0,11 & 0,09 & 0,07 & 0,04 & - \\
\hline $\begin{array}{l}\text { Lignina em detergente } \\
\text { ácido, \% }\end{array}$ & 3,43 & 3,34 & 3,16 & 2,97 & - \\
\hline Extrato etéreo, \% & 2,45 & 2,64 & 2,65 & 2,68 & - \\
\hline
\end{tabular}

NIDN - nitrogênio indigestível em detergente neutro; NIDA - nitrogênio indigestível em detergente ácido.

Valores expressos em $100 \%$ da MS

Valores expressos em $100 \%$ da MS.

*Weis et al. (1992).

**NRC (1996).

atingiram peso médio próximo ao pretendido $(400 \mathrm{~kg})$, foram pesados em jejum completo, a intervalos menores, considerando a projeção do peso de abate, com base no ganho de peso médio diário do período anterior. Os quatro animais de cada tratamento foram abatidos simultaneamente, considerando o peso médio do lote. No momento da pesagem, os animais foram avaliados quanto à condição corporal, atribuindo-se escores de 1 (muito magro) a 5 (muito gordo).

Foram coletadas amostras representativas dos componentes da dieta no início da adaptação e semanalmente durante o período experimental. As amostras foram pré-secas em estufa de ar forçado a $55^{\circ} \mathrm{C}$, por 72 horas, para determinação da matéria parcialmente seca, e posteriormente, processadas em moinho tipo Willey com peneira com crivos de $1 \mathrm{~mm}$ e armanezadas para posteriores análises bromatológicas.

Nos componentes da dieta e nas sobras de alimentos, foram determinados os teores de matéria seca, por secagem em estufa a $105^{\circ} \mathrm{C}$, durante 8 horas e, cinzas (MM), por calcinagem em mufla a $550^{\circ} \mathrm{C}$ durante 2 horas. 
O teor de nitrogênio total $(\mathrm{N})$ foi determinado pelo método de Kjeldahl, modificado conforme descrito por Kozloski et al. (2003). Os teores de extrato etéreo foram obtidos por extração com éter etílico, a $180^{\circ} \mathrm{C}$, por 2 horas. Os teores de FDN, fibra em detergente ácido (FDA), lignina em detergente ácido (LDA) foram determinados de acordo com Robertson \& Van Soest (1981). Contudo, a determinação de FDN e FDA foi feita com uso de sacos de poliéster, conforme modificação de Komarek (1993). Os teores de nitrogênio insolúvel em detergente neutro (NIDN) e nitrogênio insolúvel em detergente ácido (NIDA) foram obtidos de acordo com Licitra et al. (1996). O teor de nutrientes digestíveis totais (NDT) foi calculado segundo Weiss et al. (1992) e a energia digestível (ED) foi calculada segundo NRC (1996), em que $1 \mathrm{~kg}$ de NDT $=4,4 \mathrm{Mcal} / \mathrm{kg}$ de MS.

$\mathrm{Na}$ avaliação econômica, foram consideradas as seguintes características: custo com volumoso (A); custo com concentrado (B); custo de mão-de-obra (C); custo da compra do animal (D); custo da depreciação de maquinários com o fornecimento da alimentação $(\mathrm{E})$; custo subtotal 1 = $\mathrm{A}+\mathrm{B}+\mathrm{C}+\mathrm{D}+\mathrm{E}$; custo de oportunidade da terra $=$ [área, em ha, necessária para produção da quantidade de MS de volumoso consumida pelo animal * custo por ha/dia * $(150$ dias para produção e confecção do volumoso + período de confinamento, em dias)] (F); custo de oportunidade do capital investido $=[$ (custo subtotal 1$) *$ taxa de juros média diária da poupança * (período de lavoura + confinamento)] (G); custo subtotal $2=F+G$; custo total $=$ (custo subtotal $1+$ custo subtotal 2$)$; receita bruta $=$ receita da venda das carcaças frias; receita líquida total $=($ receita bruta com venda das carcaças frias - custo total); lucratividade total $=$ (receita líquida total/receita bruta com a venda das carcaças frias * 100); e lucratividade mensal= [lucratividade total $/$ (150 dias para obtenção do volumoso + dias de confinamento)/30]. As avaliações econômicas foram adaptadas de Pacheco et al. (2006).

Considerou-se o $\mathrm{kg}$ vivo do boi magro $=\mathrm{R} \$ 1,30 ; \mathrm{kg}$ carcaça fria $=\mathrm{R} \$ 3,60$; taxa média de juros da poupança $=$ $0,75 \%$ em 30 dias; 1 ha $=40,2 \mathrm{~kg}$ de peso vivo/ha/ano (arrendamento), ou seja, R $\$ 63,31 / \mathrm{ha} / \mathrm{ano}$, obtendo-se o custo de R $\$ 0,17 / \mathrm{ha} / \mathrm{dia} ; \mathrm{US} \$=\mathrm{R} \$ 2,24 ;$ e IGPM $-\mathrm{FNP} / \mathrm{FGV}$ (índice geral de preços de mercado FNP/ Fundação Getúlio Vargas $)=$ valor em $\mathrm{R} \$ / 0,72$ (janeiro $1980=100)$, multiplicando-se o valor do IGPM - FNP/FGV obtido pelo IGPM- FNP/FGV de qualquer mês e ano desejado para comparação dos valores em R $\$$.

Nos cálculos dos custos, foram considerados os valores reais praticados em 2005 para compra de insumos e os valores reais referentes à venda dos animais em 2006. Para estimativa do custo com mão-de-obra, no entanto, foi considerado salário rural $(\mathrm{R} \$ 450,00)$ com encargos sociais, em 2,0 horas/homem.dia para cada um dos tratamentos correspondentes ao tempo para fornecimento da alimentação, limpeza das instalações e confecção do concentrado.

Os custos de depreciação foram estimados considerando a vida útil dos equipamentos em horas e a taxa de manutenção de $10 \%$. Entretanto, não foi considerado o custo de depreciação das instalações, já que esses custos não representam as instalações usadas nos sistemas de terminação de bovinos no Brasil. No cálculo do custo do volumoso, foi incluída a produção média de 30 t/ha de matéria verde de silagem, introduzida a partir de plantio direto sem aplicação de calcário; os demais custos foram incluídos no cálculo de acordo com Pacheco et al. (2006).

Os dados foram submetidos à análise de normalidade de distribuição pelo teste de Shapiro-Wilk e avaliados quanto à homogeneidade da variância, pelo teste de Bartlett, considerando o nível de 5\% de significância. Quando essas análises preliminares foram satisfatórias, os resultados foram analisados estatisticamente por meio de análise de variância utilizando-se o procedimento GLM, com auxílio do programa estatístico SAS (1997). Foi realizado também teste de correlação e regressão polinomial. O valor do coeficiente de determinação foi calculado a partir da soma de quadrados da regressão considerada significativa dividida pela soma de quadrados de tratamento.

Os dados foram analisados de acordo com o seguinte modelo matemático geral:

$$
\mathrm{Y}_{\mathrm{ij}}=\mu+\mathrm{T}_{\mathrm{i}}+\varepsilon_{\mathrm{ij}}
$$

em que: $\mathrm{Y}_{\mathrm{ij}}=$ variáveis dependentes; $\mu=$ média de todas as observações; $\mathrm{T}_{\mathrm{i}}=$ efeito dos tratamentos; e $\varepsilon_{\mathrm{ij}}=$ erro experimental residual (erro b). No estudo da regressão polinomial, foi utilizado o seguinte modelo:

$$
Y_{i j k}=\beta_{0}+\beta_{1} X_{i}+\beta_{2} X_{i}^{2}+\alpha_{i j k}+\varepsilon_{i j k}
$$

no qual $Y_{\mathrm{ijk}}=$ variáveis dependentes; $\beta$ 's = coeficientes de regressão; $X_{\mathrm{ijk}}=$ variáveis independentes; $\alpha_{\mathrm{ijk}}=$ desvios da regressão; e $\varepsilon_{\mathrm{ijk}}=$ erro aleatório residual.

\section{Resultados e Discussão}

A idade final diminuiu linearmente com o aumento dos níveis de concentrado na dieta, de modo que $1 \%$ a mais de concentrado promoveu diminuição de 0,03 meses (Tabela 2). Os animais alimentados com $22 \%$ de concentrado na dieta não puderam ser abatidos com idade média inferior a 16 meses, pois tiveram desempenho inferior, em decorrência do baixo peso vivo ao início do confinamento. De forma geral, quando o confinamento de bovinos visa abater animais superjovens, deve-se ter cuidados especiais com o peso vivo inicial e com a proporção de concentrado a ser 
utilizada, uma vez que, em condições semelhantes às deste estudo, o período que os animais alimentados com nível baixo de concentrado na dieta levam para atingir a condição de abate pode ser muito longo e ultrapassar a idadereferência para abate.

O peso final, de outra maneira, não foi influenciado pelos níveis de concentrado na dieta, uma vez que o abate dos animais foi pré-determinado em aproximadamente $400 \mathrm{~kg}$. O escore de condição corporal não diferiu significativamente entre os níveis de concentrado utilizados na dieta, uma vez que os animais foram abatidos em estágio de desenvolvimento corporal semelhante.

Outro aspecto interessante é a relação entre a diminuição do período de confinamento com o aumento do nível de concentrado na dieta, visto que os dias de confinamento foram fortemente relacionados à lucratividade na terminação $(\mathrm{r}=-0,95 ; \mathrm{P}<0,05)$. As demais variáveis não foram influenciadas $(\mathrm{P}>0,05)$ pelos níveis de concentrado, pois foram pré-estabelecidas para o início do experimento.

O consumo de matéria seca $(\mathrm{kg} / \mathrm{dia})$ não foi influenciado $(\mathrm{P}>0,05)$ pelos níveis de concentrado utilizados na dieta (Tabela 3) e foi semelhante aos resultados obtidos por Carvalho et al. (1997), Rodriguez et al. (1996) e Bürguer et al. (2000), atribuído por esses autores aos coeficientes de digestibilidade das dietas. Por outro lado, Tibo et al. (2000) verificaram aumento do consumo de matéria seca $(\mathrm{kg} / \mathrm{dia})$ com o aumento do nível de concentrado na dieta, como resultado do aumento no consumo de energia.

Os consumos de matéria seca em porcentagem do peso vivo e tamanho metabólico foram mais bem explicados por equações de regressão quadráticas e aumentaram até os níveis de 67 e $75 \%$ de concentrado na dieta, respectivamente. Araújo et al. (1998), estudando várias proporções de volumoso:concentrado para bezerros holandeses,

Tabela 2 - Idade inicial e final, dias em confinamento, peso inicial e final, escore de condição corporal inicial e final de bovinos alimentados com diferentes níveis de concentrado na dieta

\begin{tabular}{|c|c|c|c|c|c|c|c|}
\hline \multirow[t]{2}{*}{ Variável } & \multicolumn{4}{|c|}{ Nível de concentrado } & \multirow[t]{2}{*}{ Erro-padrão } & \multirow[t]{2}{*}{$\mathrm{R}^{2}$} & \multirow[t]{2}{*}{ Equação de regressão } \\
\hline & 22 & 40 & 59 & 79 & & & \\
\hline Idade inicial (meses) & 9,45 & 8,85 & 9,52 & 9,45 & 0,40 & - & $\mathrm{ns}$ \\
\hline Idade final (meses) & 16,60 & 15,00 & 14,80 & 14,80 & 0,38 & 0,51 & $\hat{\mathrm{Y}}=16,79-0,0302^{* *} \mathrm{NC}$ \\
\hline Dias em confinamento & 199,00 & 171,00 & 140,00 & 140,00 & 0,00 & - & - \\
\hline Peso inicial $(\mathrm{kg})$ & 191,25 & 187,00 & 197,50 & 194,00 & 15,76 & - & $\mathrm{ns}$ \\
\hline Peso final $(\mathrm{kg})$ & 400,75 & 407,25 & 392,75 & 394,75 & 30,21 & - & $\mathrm{ns}$ \\
\hline $\begin{array}{l}\text { Escore de condição } \\
\text { corporal inicial (1 a } 5)\end{array}$ & 2,84 & 2,81 & 2,80 & 2,85 & 0,06 & - & $\mathrm{ns}$ \\
\hline Escore de condição final (1 a 5) & 3,84 & 3,80 & 3,51 & 3,91 & 0,15 & - & $\mathrm{ns}$ \\
\hline
\end{tabular}

${ }^{* *} \mathrm{P}<0,01 ;{ }^{\mathrm{ns}} \mathrm{P}>0,05$

Tabela 3 - Consumo de nutrientes, ganho de peso médio diário e conversão alimentar de bovinos mantidos com dietas com diversos níveis de concentrado

\begin{tabular}{|c|c|c|c|c|c|c|c|}
\hline \multirow[t]{2}{*}{ Variável } & \multicolumn{4}{|c|}{ Nível de concentrado } & \multirow[t]{2}{*}{ Erro-padrão } & \multirow[t]{2}{*}{$\mathrm{R}^{2}$} & \multirow[t]{2}{*}{ Equação de regressão } \\
\hline & 22 & 40 & 59 & 79 & & & \\
\hline Matéria seca $(\mathrm{kg})$ & 6,11 & 6,74 & 7,24 & 7,15 & 0,51 & - & $\mathrm{ns}$ \\
\hline Matéria seca ( $\mathrm{g}$ de $\mathrm{MS} / \mathrm{PV}^{0,75}$ ) & 85,34 & 94,27 & 102,14 & 100,36 & 5,68 & 0,63 & $\hat{\mathrm{Y}}=65,11+1,07 \mathrm{NC}-0,008^{*} \mathrm{NC}^{2}$ \\
\hline Proteína bruta $(\mathrm{kg})$ & 0,95 & 1,12 & 1,14 & 1,05 & 0,07 & - & $\mathrm{ns}$ \\
\hline Energia digestível $(\mathrm{Mcal} / \mathrm{dia})^{4}$ & 18,28 & 21,43 & 24,05 & 23,59 & 1,57 & 0,46 & $\hat{\mathrm{Y}}=17,01+0,097^{* * *} \mathrm{NC}$ \\
\hline Fibra em detergente neutro $(\mathrm{kg})$ & 3,28 & 3,26 & 2,80 & 2,01 & 0,20 & 0,88 & $\hat{\mathrm{Y}}=3,96-0,0225^{* * *} \mathrm{NC}$ \\
\hline $\begin{array}{l}\text { Fibra em detergente neutro } \\
\text { (kg de } \mathrm{MS} / 100 \mathrm{~kg} \text { de } \mathrm{PV} \text { ) }\end{array}$ & 1,11 & 1,10 & 0,96 & 0,68 & 0,04 & 0,86 & $\hat{\mathrm{Y}}=1,33-0,0074^{* * *} \mathrm{NC}$ \\
\hline Ganho médio diário $(\mathrm{kg})$ & 1,05 & 1,29 & 1,40 & 1,43 & 0,11 & 0,47 & $\hat{\mathrm{Y}}=0,966+0,0065^{* *} \mathrm{NC}$ \\
\hline
\end{tabular}

$* \mathrm{P}<0,05 ; * * \mathrm{P}<0,01 ; \quad{ }^{* * *} \mathrm{P}<0,0001 ;{ }^{\mathrm{ns}} \mathrm{P}>0,05$. 
verificaram comportamento quadrático do consumo de matéria seca em porcentagem do peso vivo com a adição crescente de volumoso (10 a 90\%), de modo que o ponto de máxima foi observado para $33,3 \%$ de volumoso na dieta. Tibo et al. (2000), no entanto, observaram aumento linear no consumo de matéria seca em porcentagem do peso vivo com o aumento linear no consumo de energia. Por outro lado, Bürger et al. (2000) observaram redução do consumo com o aumento de concentrado na dieta, ocasionada pelo consumo de NDT. Costa et al. (2005) afirmaram que a divergência de resultados entre trabalhos com avaliação de níveis de concentrado na dieta permite inferir que o consumo de matéria seca é uma variável complexa, que pode ser afetada por diversos fatores, como o animal, o alimento, a alimentação e as condições climáticas, que interagem e passam a ser determinantes.

O conteúdo de fibra na ração reduz o consumo voluntário, por promover o enchimento do rúmen, quando as rações contêm alto teor de FDN (Van Soest \& Mertens, 1984). Rações com alto teor de concentrado (acima de $75 \%$ na MS), baixo teor de fibra (abaixo de $25 \%$ ) e digestibilidade elevada (acima de 66\%) podem resultar em menor consumo de matéria seca, uma vez que as necessidades energéticas são atendidas em menores níveis de consumo (Van Soest, 1994). Mertens (1994) afirmou que a ingestão é limitada pelo efeito físico de enchimento quando o consumo de FDN é de 11 a $13 \mathrm{~g} / \mathrm{kg}$ PV. Neste experimento, o consumo de FDN foi 11,$1 ; 11,0 ; 9,6$ e $6,8 \mathrm{~g} / \mathrm{kg} \mathrm{PV}$ para os animais que receberam 22; $40 ; 59$ e $79 \%$ de concentrado, respectivamente. Neste estudo, o consumo de matéria seca foi limitado pelo enchimento do rúmen no caso das dietas com menores proporções de concentrado, enquanto, nas dietas com maiores níveis, o limite foi a demanda fisiológica de energia para o animal.

O consumo de proteína bruta não foi influenciado pelos níveis de concentrado na dieta $(\mathrm{P}>0,05)$, mas foi determinado pelos teores semelhantes de $\mathrm{PB}$ nas dietas e pelo consumo de matéria seca. O consumo de FDN, por outro lado, respondeu negativamente e de forma linear ao aumento do nível de concentrado na dieta, o que pode ser atribuído aos menores teores de FDN nas dietas com maiores proporções de concentrado. Esses resultados são semelhantes aos encontrados por Rodriguez et al. (1996), Carvalho et al. (1997) e Signoretti et al. (1999a).

A ingestão de energia digestível aumentou linearmente com a elevação da proporção de concentrado na dieta, o que está relacionado aos teores de energia das dietas, aliado ao consumo de matéria seca. Os resultados deste estudo são similares aos encontrados por Tibo et al. (2000) e Cardoso et al. (2000). Ítavo et al. (2002), no entanto, não verificaram diferenças no consumo de NDT e atribuíram esse fato à alta quantidade de nurientes digestíveis $(2,24 \mathrm{~kg} / \mathrm{dia})$ provenientes do volumoso.

A conversão alimentar expressa a quantidade de matéria seca necessária para cada quilograma de peso vivo depositado e a diminuição desta característica é desejável na produção animal, pois pode representar menor custo por quilo de ganho e maior lucratividade do sistema produtivo. Neste estudo, o aumento do nível de concentrado na dieta promoveu diminuição linear da conversão alimentar, como resultado da maior densidade energética das dietas com maiores proporções de concentrado. O ganho médio diário, por sua vez, respondeu de forma linear ao aumento de concentrado na dieta, e aumentou em média $0,0065 \mathrm{~kg}$ a cada $1 \%$ a mais de concentrado, comportamento semelhante aos descritos por Berchielli et al. (1989), Ferreira et al. (1998) e Signoretti et al. (1999b). Segundo o NRC (1996), maiores taxas de ganho de peso implicam maiores exigências de energia para crescimento, que, neste trabalho, foram supridas com o aumento do consumo de energia digestível.

O custo com aquisição de animais e a receita bruta não foram influenciados $(\mathrm{P}>0,05)$ pelos níveis de concentrado na dieta (Tabela 4), uma vez que os animais foram adquiridos com peso inicial semelhante e abatidos com mesmo peso vivo médio. O custo de oportunidade do capital investido, por outro lado, respondeu de forma quadrática ao aumento do nível de concentrado na dieta, com ponto de mínima no nível de $63 \%$ de concentrado.

A diminuição nos dias de confinamento e no fornecimento de volumoso com a elevação do nível de concentrado na dieta foi o principal responsável pela diminuição linear dos custos com mão-de-obra, depreciação de equipamentos, custo com volumoso e custo de oportunidade da terra.

O aumento do nível de concentrado na dieta influenciou $(\mathrm{P}<0,05)$ o custo de fornecimento de concentrado e o custo total, que aumentaram linearmente e estiveram relacionados aos maiores custos do concentrado em relação à fração volumosa. Signoretti et al. (1999b) verificaram menor custo por arroba no nível de $60 \%$ de concentrado em animais abatidos aos $300 \mathrm{~kg}$ e que o custo da arroba foi resultado do menor período de confinamento (188 dias). A receita líquida, por sua vez, foi mais bem explicada por equação linear decrescente e refletiu o aumento no custo total.

A lucratividade do confinamento para terminação de bovinos é variável, visto que que é influenciada pelas variações impostas pelo mercado sobre os preços dos insumos e produto final. Essa variabilidade pode ser também visualizada nitidamente entre diferentes regiões do país, uma vez que os insumos e produtos cárneos respondem à variações regionalizadas do mercado. Neste 
Tabela 4 - Análise econômica da utilização de cada nível de concentrado na dieta

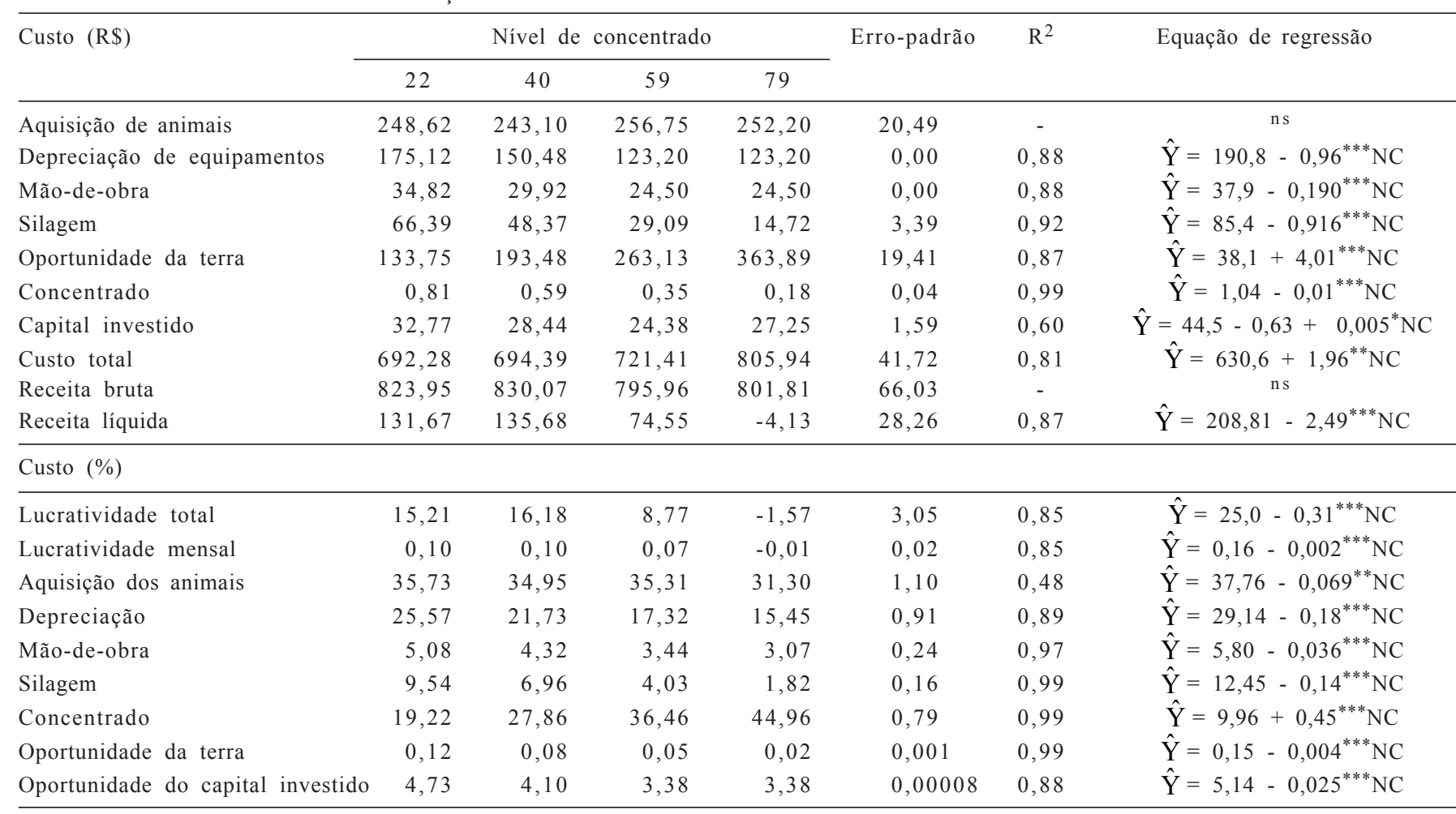

${ }^{*} \mathrm{P}<0,05 ;{ }^{* *} \mathrm{P}<0,01 ;{ }^{* * *} \mathrm{P}<0,0001 ;{ }^{\text {ns }} \mathrm{P}>0,05$.

estudo, a lucratividade do período e a lucratividade mensal se ajustaram melhor a equações de regressão lineares decrescentes com o aumento de concentrado na dieta, resultado da diminuição na renda líquida. Gesualdi Jr. et al. (2000) citam que, a partir de custos viáveis de volumoso e concentrado, e havendo remuneração por carcaças de melhor qualidade, o sistema de alimentação que utiliza maior nível de concentrado tende a se tornar mais eficiente, pois reduz o tempo gasto em confinamento e os custos de produção, visto que a maior parte destes custos é decorrente da alimentação. Os resultados deste estudo são contrários aos reportados por esses autores, visto que os custos de produção aumentaram com a participação do concentrado na dieta, em resposta à elevação dos custos com concentrado. Essas diferenças podem estar associadas ao baixo preço do concentrado utilizado por aqueles autores, já que na simulação um dos preços considerados para o concentrado foi equivalente ao preço do volumoso e o outro foi superior em apenas U\$ 0,05 .

Os custos de produção, como a aquisição de animais, depreciação de equipamentos, mão-de-obra, volumoso, custo de oportunidade da terra e do capital investido, diminuíram com o aumento do nível de concentrado na dieta, em decorrência do aumento relativo dos custos com concentrado aliado à diminuição no tempo de confina- mento. À medida que o nível de concentrado na dieta aumentou, os custos com concentrado superaram os custos com aquisição dos animais. Segundo Pacheco et al. (2006), desconsiderando o valor de compra do animal, a alimentação é a fração de maior custo na produção e, na alimentação, o concentrado é o item mais oneroso. Por outro lado, Rodriguez Filho et al. (2002) verificaram que os custos, em ordem de importância, foram os referentes a alimentação, custo do bezerro, mão-de-obra, produtos veterinários, energia, reparos e impostos.

Para todos os preços simulados, ocorreu diminuição linear da renda líquida e lucratividade com o aumento do concentrado na dieta (Tabela 5). Nos maiores níveis de concentrado, a terminação dos animais foi inviabilizada economicamente quando o preço do concentrado atingiu cerca $26 \%$ do preço do boi gordo e, quando o preço do concentrado representou $53 \%$ do valor do preço do boi gordo, todos os níveis de concentrado utilizados se tornaram economicamente inviáveis. Signoretti et al. (1999b) citaram que a viabilidade da produção de bezerros da raça holandesa alimentados com diferentes níveis de volumoso depende da análise do preço do volumoso e concentrado, assim como, a qualidade nutricional dos alimentos, de forma a aumentar a produtividade e lucratividade. 
Tabela 5 - Renda líquida e lucratividade total de cada nível de concentrado

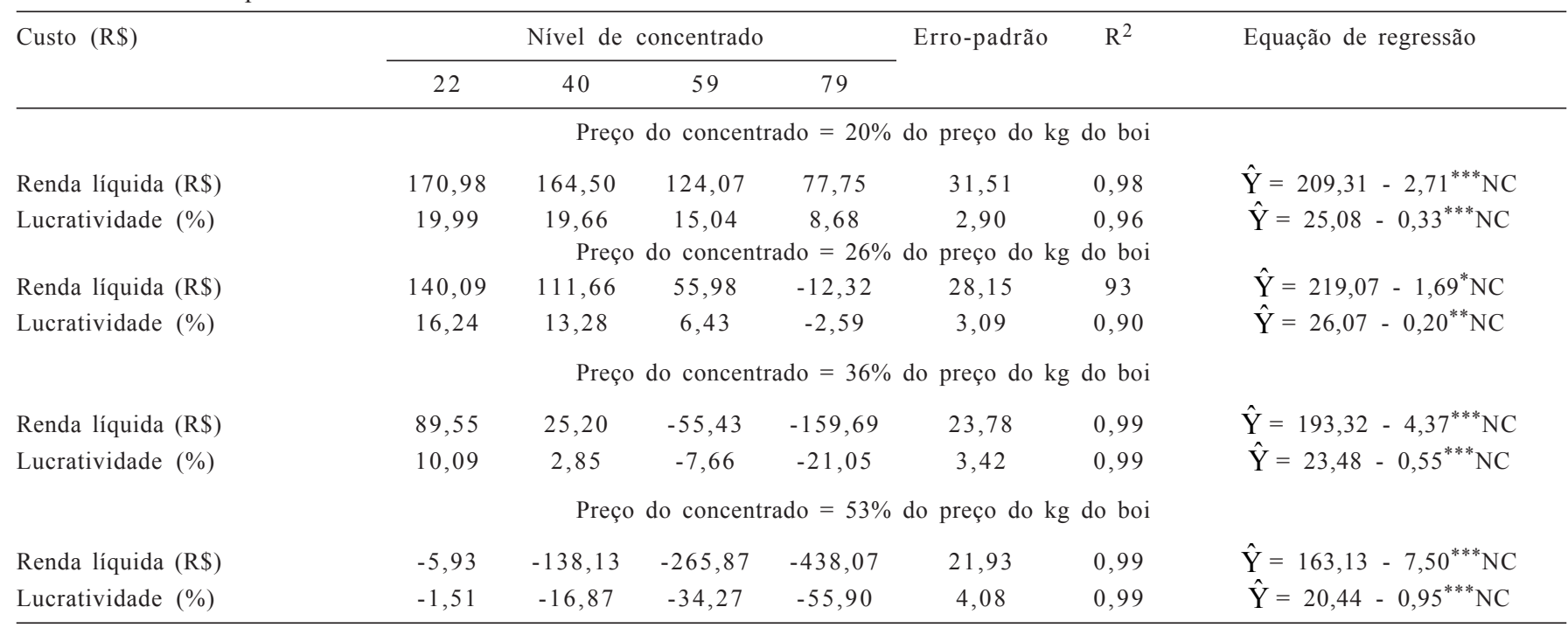

${ }^{*} \mathrm{P}<0,05 ;{ }^{* *} \mathrm{P}<0,01 ;{ }^{* * *} \mathrm{P}<0,0001 ;{ }^{1} \mathrm{R} \$ ;{ }^{2 \%}$; preço do boi $=\mathrm{R} \$ 1,75 / \mathrm{kg}$.

\section{Conclusões}

O aumento da proporção de concentrado de 22 para $79 \%$ em dietas à base de silagem de milho melhora o desempenho animal, mas reduz a lucratividade da terminação de tourinhos em confinamento com 14 a 16 meses de idade.

\section{Literatura Citada}

ASSOCIATION OF OFFICIAL ANALYTICAL CHEMISTS - AOAC. Official methods of analysis. 12.ed. Washington, D.C.: 1995. $1094 \mathrm{p}$.

ARAÚJO, G.G.L.; COELHO DA SILVA, J.F.; VALADARES FILHO, S.C. et al. Consumo e digestibilidade total dos nutrientes de dietas contendo diferentes níveis de volumoso, em bezerros. Revista Brasileira de Zootecnia, v.27, n.2, p.345-354, 1998.

BERCHIELLI, T.T.; ANDRADE, P.; PINOTTI, R.F. et al. Níveis de concentrado e uréia na alimentação de bovinos nelore com bagaço de cana-de-açucar hidrolizado. Revista da Sociedade Brasileira de Zootecnia, v.18, n.3, p.205-211, 1989.

BÜRGER, P.J.; PEREIRA, J.C.; COELHO DA SILVA, J.F. et al. Consumo e digestibilidade aparente total e parcial em bezerros holandeses alimentados com dietas contendo diferentes níveis de concentrado. Revista Brasileira de Zootecnia, v.29, n.1, p.206-214, 2000.

CARDOSO, R.C.; VALADARES FILHO, S.C.; SILVA, J.F.C. et al. Consumo e digestibilidades aparentes totais e parciais de rações contendo diferentes níveis de concentrado, em novilhos F1 Limousin x Nelore. Revista Brasileira de Zootecnia, v.29, n.6, p.1832-1843, 2000.

CARVALHO, A.U.; VALADARES FILHO, S.C.; COELHO DA SILVA, J.F. et al. Níveis de concentrado em dietas de zebuínos. Consumo e digestibilidade aparente. Revista Brasileira de Zootecnia, v.26, n.5, p.986-995, 1997.

COSTA, M.A.L.; VALADARES FILHO, S.; PAULINO, M.F. et al. Desempenho, digestibilidade e características de carcaça de novilhos zebuínos alimentados com dietas contendo diferentes níveis de concentrado. Revista Brasileira de Zootecnia, v.34, n.1, p.268-279, 2005.
FERREIRA, M.A.; VALADARES FILHO, S.C.; COELHO DA SILVA, J.F. et al. Consumo, conversão alimentar, ganho de peso e características da carcaça de bovinos F1 Simental x Nelore. Revista Brasileira de Zootecnia, v.28, n.2, p.343-351, 1998.

GESUALDI JR., A.; PAULINO, M.F.; VALADARES FILHO, S.C. et al. Níveis de concentrado na dieta de novilhos $\mathrm{F} 1$ Limousin $\mathrm{x}$ Nelore: consumo, conversão alimentar e ganho de peso. Revista Brasileira de Zootecnia, v.29, n.3, p.1458-1466, 2000.

ÍTAVO, L.C.V.; VALADARES FILHO, S.C.; SILVA, F.S. et al. Consumo e digestibilidades aparentes totais e parciais de nutrientes em novilhos alimentados com dietas contendo vários níveis de concentrado. Revista Brasileira de Zootecnia, v.31, n.3, p. 1543-1552, 2002 .

KOMAREK, A. R. A fiber bag procedure for improved efficiency of fiber analyses. Journal of Dairy Science, v.76, p.250, 1993 (suppl. 1).

KOZLOSKI, G.V.; PEROTTONI, J.; ROCHA, J.B.T. Potencial nutricional assessment of dwarf elefhant grass (Pennisetun purpureum, Schum. Mott) by chemical composition, digestion and net portal flux of oxygen in cattle. Animal Feed Science Technology, v.29, n.3, p.29-40, 2003.

LICITRA, G.; HERNANDEZ, T.M.; Van SOEST, P. J. Standarization of procedures for nitrogen fractionation of ruminant feeds. Animal Feed Science Technology, v.57, p.347-358, 1996.

MERTENS, D.R. 1994. Regulation of forage intake. In: FAHEY JR., G.C. (Ed.). Forage quality, evaluation and utilization. Madison: American Society of Agronomy. p.450-493.

NATIONAL RESEARCH COUNCIL - NRC. Nutrients requirements of beef cattle. 7.ed. Washington, D.C.: 1996. 242p.

PACHECO, P.S.; RESTLE, J.; VAZ, F.N. et al. Avaliação econômica em confinamento de novilhos jovens e superjovens de diferentes grupos genéticos. Revista Brasileira de Zootecnia, v.35, n.1, p.309-320, 2006.

RODRIGUEZ, L.R.R.; FONTES, C.A.A.; JORGE, A.M. et al. Consumo de rações contendo quarto níveis de concentrado por bovinos holandeses e nelores e por bubalinos. Revista da Sociedade Brasileira de Zootecnia, v.25, n.3, p.569-581, 1996.

RODRIGUEZ FILHO, R.; MANCIO, A.B.; GOMES, S.T. et al. Avaliação econômica do confinameno de novilhos de origem leiteira, alimentados com diferentes níveis de concentrado e de cama de frango. Revista Brasileira de Zootecnia, v.31, n.5, p.2055-2069, 2002. 
ROBERTSON, J.B.; Van SOEST, P.J. The detergent system of analysis. In: JAMES, W.P.T.; THEANDER, O. (Eds.). The analysis of dietary fibre in food. New York: Marcel Dekker, 1981. p.123-158.

STATISTICAL ANALYSIS SYSTEM - SAS. User's guide. SAS for Windows. Cary: SAS Institute, 1997. 46p.

SIGNORETTI, R.D.; COELHO DA SILVA, J.F.; VALADARES FILHO, S.C. et al. Consumo e digestibilidade em bezerros da raça holandesa alimentados com dietas contendo diferentes níveis de volumoso. Revista Brasileira de Zootecnia, v.28, n.1, p.169-177, 1999a.

SIGNORETTI, R.D.; COELHO DA SILVA, J.F.; VALADARES FILHO, S.C. et al. Crescimento, conversão alimentar e rendimento de carcaça de bezerros da raça holandesa alimentados com dietas contendo diferentes níveis de volumoso. Revista Brasileira de Zootecnia, v.28, n.1, p.185-194, 1999b.
TIBO, G.C.; VALADARES FILHO, S.C.; VALADARES, R.F.D. et al. Níveis de concentrado em dietas de ovilhos mestições F1 Simental x Nelore. 1. Consumo e digestibilidade. Revista Brasileira de Zootecnia, v.29, n.3, p.910-920, 2000.

Van SOEST, P.J. Nutritional ecology of the ruminant. 2.ed. Ithaca, NY, Cornell University Press. 476p. 1994.

Van SOEST, P.J., MERTENS, D.R. The use of neutral detergent fiber versus acid detergent fiber in balancing dairy rations. In: TECHNICAL SYMPOSIUM, 1984, Fresmo. Proceedings... Fresmo: Monsanto - Nutrition Chemicals Division, 1984. p.75-92.

WEISS, W.P.; CONRAD, H.R.; ST. PIERRE, N.R. A theoreticallybased model for predicting total digestible nutrient values of forages and concentrates. Animal Feed Science and Technology, v.39, p.95-110, 1992. 